DERLEME

Sinus ogmentasyon

komplikasyonları ve tedavi önerileri

\section{Complications of sinus augmentation and treatment suggestions}

\section{Dr. Ebru Özkan Karaca}

Yeditepe Üniversiteși, Diş Hekimliği Fakültesi

Periodontoloji A.D., İstanbul

\section{Doç. Dr. Hare Gürsoy}

Yeditepe Üniversitesi, Diş Hekimliği Fakültesi Periodontoloji A.D., İstanbul

\section{Dr. Ogül Leman Tunar}

Yeditepe Üniversiteși, Diş Hekimliği Fakültesi Periodontoloji A.D., İstanbul

\section{Prof. Dr. Bahar Eren Kuru}

Yeditepe Üniversitesi, Diş Hekimliği Fakültesi Periodontoloji A.D., İstanbul

\section{Geliş Tarihi : 02 Haziran 2016}

Kabul tarihi: 17 Ağustos 2016

DOI: 10.5505/yeditepe.2016.03511

\section{Yazışma Adresi:}

\section{Dr. Ebru Özkan Karaca}

Yeditepe Üniversitesi, Diş Hekimliği Fakültesi, Periodontoloji A.D.

Bağdat cad. No:238 Göztepe- İSTANBUL

Tel: 05322964525

E-posta: esmaebrukaraca@gmail.com

\section{ÖZET}

Sinüs ogmentasyonu tekniği, posterior maksiller bölgenin rehabilitasyonunda en sık kullanılan tekniktir. Sinüs ogmentasyonu, etkili ve sonucu öngörülebilir bir tedavi protokolü olarak kabul edilse de, komplikasyonlara açık bir cerrahi yöntemdir. Komplikasyonlar, cerrahi işem sırasında ya da cerrahi işlem sonrasında ortaya çıkabildiği gibi birbirleriyle bağlantılı olarak da oluşabilirler. Bu derlemenin amacı sinüs ogmentasyon işlemi sırasında ve sonrasında meydana gelebilecek komplikasyonları ve bu komplikasyonları önlemek amacıyla operasyon öncesi ve sonrasında alınabilecek önlemleri değerlendirmektir.

Anahtar Kelimeler: Sinüs ogmentasyonu, kemik grefti, membran perforasyonu, septa, tedavi.

\section{SUMMARY}

Sinus augmentation is the most frequently utilized methodology for the rehabilitation of posterior maxillary region. Although sinus augmentation can be considered as an efficient and predictable technique, it is also prone to various complications. Complications may arise during or after surgical procedures or can be inter-related. The purpose of this review is to evaluate possible complications during or after sinus augmentation as well as pre and post operative precautions for the prevention of complications.

Key words: Sinus augmentation, bone graft, membrane perforation, septa, treatment. 


\section{Sinus ogmentasyonu komplikasyonları ve tedaviönerileri}

Diş siz maksiller bölgenin rehabilitasyonu için dental implantların kullanılması, maksiller sinüse olan yakınlık ve azalmış kemik yüksekliği sebebiyle zorlaşmaktadır.1 Bu zorlukların üstesinden gelmek için kullanılan sinüs ogmentasyonu, posterior maksiller bölgenin rehabilitasyonunda en sık kullanılan tekniktir. ${ }^{2}$ Maksiller sinüsün protetik amaçlar için kemik grefti ile yükseltilmesi ilk kez Boyne ${ }^{3}$ tarafından 1960 yılında önerilmiş, 1980 yılında ise Boyne ve James ${ }^{4}$, sinüs tabanının greftlenmesini ilk kez rapor etmişlerdir. Bu amaçla kullanılan yöntemler açık teknik (lateral pencere yada Cadwell Luc) ve kapalı teknik (osteotom) olarak ikiye ayrılmaktadır. Açık teknik, maksiller sinüs duvarında bir kemik penceresi açılarak, sinüs membranının yükseltilmesini takiben oluşturulan alana, greft materyalinin uygulanmasıdır. ${ }^{4}$ Kapalı teknik ise, kret üzerinden osteotomlar kullanılarak greftin yerleştirilebileceği alanın yaratıldığı daha az invaziv bir yöntemdir. ${ }^{5}$ Hangi tekniğin kullanılacağına, kalan kemik yüksekliği ve dental implantların primer stabilitesinin sağlanması kriterleri göz önünde bulundurularak karar verilmektedir. ${ }^{6}$ Son yıllarda yapılan sistematik derlemelerde, her iki tekniğin kullanıldığı sinüs ogmentasyonu sonrası yapılan implant sağ kalım oranının, hastanın kendi kemiğine yapılan implantların sağ kalım oranlarıyla benzer olduğu rapor edilmektedir. ${ }^{7-11}$

Maksiller kemiğin sadece dikey mesafesinin arttırılması, tek başına başarı kriteri olarak olarak değerlendirilmemektedir. Yapılacak olan tedavinin üç boyutlu olarak planlanması gerekmektedir.11 Bu şekilde yapılmış olan bir tedavi protokolü, klinisyen ve hasta açısından konfor, fonksiyon, estetik ve uzun dönem başarıyı beraberinde getirmektedir. Bireye ait anatomik ve patolojik farklılıkları analiz edebilmek, en iyi ve uzun süreli tedavi sonucunu elde edebilmek için sinüs ogmentasyonu öncesinde maksiller sinüsün çok iyi değerlendirilmesi gereklidir. ${ }^{12}$

Sinüs ogmentasyonu cerrahisi etkili ve sonucu öngörülebilir bir tedavi protokolü olarak görülse de, komplikasyonlara açık bir yöntemdir. Komplikasyonlar cerrahi sırasında ya da cerrahi işlem sonrasında ortaya çıkabildiği gibi birbirleriyle bağlantılı da olabilirler. ${ }^{11}$

Bu derlemenin amacı sinüs ogmentasyonu işlemi sırasında ve sonrasında meydana gelebilecek komplikasyonları ve komplikasyonu önlemek amacıyla operasyon öncesi ve sonrasında alınabilecek önlemleri değerlendirmektir.

\section{Bireye ait komplikasyonlar ve tedaviöncesi değerlendirmeler}

Sinüs cerrahisi öncesi yapılacak değerlendirmeler mutlaka medikal ve dental anamnezi içermelidir. Radyoterapi ve/ veya kemoterapi gören immün sistemi baskılanmış hastalar, kontrol edilemeyen diyabet, immün yetersizlik, çoklu ilaç kullanımı gibi sistemik durumlar kesin kontrendikasyon olarak görülmektedir.13 Yapılan çalışmalarda kontrol altında olan Tip II diyabetli hastalarda görülen implant sağ kalım oranlarının diyabeti olmayan bireylerinkiyle benzer olduğu saptanmıştır. ${ }^{14}$

Aktif periodontal hastalık, aktif sinüzit, büyük kistler ve uzun zamandır devam eden kronik sinüzit varlığı ciddi risk faktörleri arasında yer almaktadır., ${ }^{15,16}$ Sinüs ogmentasyonu öncesinde teşhis ve tedavi alternatiflerinin oluşturulmas için bölgenin üç boyutlu olarak bilgisayarlı tomografi (BT) ile görüntülenmesi tedavinin başarısında büyük önem taşımaktadır. ${ }^{17}$ Panoramik radyografiler bu amaçla uzun zaman kullanılmış olsa da, bölgenin üç boyutlu değerlendirilmesi ve sinüs patolojilerinin saptanmasında yetersiz kalmaktadır. İlk kez Mozzo ve ark. ${ }^{18}$ tarafından bulunan konik ışınlı bilgisayarlı tomografiler (KIBT) dental işlemler için oldukça popüler olmuş ve yaygın kullanım alanı bulmuştur. Panoramik radyografilere kıyasla anatomik yapıları, morfolojik yapıyı ve kemik boyutlarını daha kesin ve çarpıtma olmaksızın vermesi, aynı zamanda geleneksel BT lere göre hastaya daha az radyasyon verilmesi avantajları arasında yer almaktadır. ${ }^{19}$ Operasyon öncesi alınan KIBT'ler, osteomeatal kompleksin durumunu, sinüsün havalanmasını ve sinüste bulanan septa varlığını teşhis etmeye olanak sağlar. ${ }^{20}$ 
Sigaranın periodontal hastalıklar ve cerrahi işlemler için risk faktörü olduğu ve implantların sağ kalım oranını olumsuz etkilediği yapılan çalışmalarda ortaya konmuştur. ${ }^{21,22}$ Pjeruttson ve ark. ${ }^{7}$ tarafından yapılan sinüs ogmentasyonu çalışmalarının değerlendirildiği sistematik derlemede, sigara içenlerde meydana gelen implant başarısızlıklarının içmeyen bireylere göre iki kat fazla olduğu bildirilmiştir.

Tedavi öncesinde sert dokular kadar yumuşak dokuların da değerlendirilmesi, hastanın oklüzyon kontrolünün yapılması ve parafonksiyonel alışkanlıkların kontrol edilmesi tedavinin başarııında büyük önem taşımaktadır. Bu tip titiz bir değerlendirmenin tedavinin ilk aşamasında yapılmaması, idealden fazla cerrahi girişim yapılması, operasyon sonrası komplikasyon ve implant kaybı gibi durumlarla karşılaşımasını beraberinde getirir.1 $\mathrm{Bu}$ nedenle biolojik prensipler ve alternatif tedavilerin göz önünde bulundurulduğu kapsamlı bir inceleme yapılmalı ve hastanın operasyon için uygun bir aday olup olmadığı değerlendirilmeden tedaviye başlanmamalıdır.

\section{Cerrahi işlem sırasında meydana gelen komplikasyonlar}

Sinüs membranı perforasyonu

Sinüs ogmentasyonu cerrahisi sırasında en sık görülen komplikasyon sinüs membranının perfore edilmesidir. ${ }^{23,24}$ Lite- ratürde yapılan çalışmalarda bu oranın \%12 ile \%44 arasında değiştiği, ortalamanın ise \%20-25 arasında olduğu bildirilmektedir. ${ }^{23-28}$ Sinüs membranı, maksiller sinüsün içini kaplayan 0.13-0.5 mm kalınlığında çok katı yassı epitel içeren müköz bir membrandır. ${ }^{29}$ Membranın az sayıda elastik fibril içermesi kemik duvarlarından elevasyonunu zorlaştırmaktadır. Sinüs ogmentasyonu işlemi sırasında, membranın eleve edilmesiyle oluşturulan alan ile alveol kemiği arasında kalan boşluğa greft materyali uygulanır. Sinüs membran perforasyonuna sebep olan başıca risk faktörleri, sinüste septa varlığı (underwood septa), sinüs duvarlarının açısı, membranın kalınlığı, osteotomi veya membranın elevasyon işlemi sırasındaki uygulama hataları olarak sıralanabilir. ${ }^{23,24,30,31}$ Yapılan çalışmalar, membran per- forasyonunun, post-operatif akut ve kronik sinüzit, ödem, kanama, greft materyalinin rezorbsiyonu ve normal sinüs fonksiyonlarının engellenmesi gibi sonuçları olduğunu ortaya koymaktadır. ${ }^{23,24,26,32}$ Bununla birlikte membran perforasyonlarının impantların başarısındaki etkisi konusunda literatürde görüş birliği sağlanamamıştır. Del Fabbro ve ark. ${ }^{8}$ tarafından son yıllarda yapılan sistematik derlemede, 3 yıllık implant başarısının lateral pencere tekniğinde \%93.7, osteotomi tekniğinde ise \%97.2 olarak bildirilmiştir. Benzer şekilde yapılan çalışmalarda Ardekian ve ark. ${ }^{33}$ dört yıllık implant başarısını \%94 olarak rapor etmişler, perforasyon olan ve olmayan ogmentasyon bölgeleri arasında istatistiksel bir fark olmadığını ortaya koymuşlardır. Barone ve ark.$^{34} 70$ hastada yaptıkları çalışmada, \%94.3 lük implant başarısı sağlarken, membran perforasyonunun implant başarısına olumsuz bir etki yaratmadığını bildirmişlerdir. Buna karşın Proussaefs ve ark. ${ }^{35}$ perforasyon oluşan sinüs ogmentasyonu sonrası elde edilen implant başarısını \%69.5, membranın sağlam kaldığı cerrahi sonrası implant başarısını ise $\% 100$ olarak rapor etmişlerdir.

Benzer şekilde yapılan çalışmalarda Nolan ve ark. ${ }^{36}$ ve Hernandez ve ark. ${ }^{37}$ membran perforasyonu oluşan tarafta implant kaybının istatistiksel olarak anlamlı derece fazla olduğunu bildirmişlerdir.

Literatürde yapılan çalışmalar incelendiğinde, membran perforasyonunun kemik penceresi oluşturulurken döner alet kullanımı ya da membranın iç duvarlardan elevasyonu sırasında meydana geldiğini ortaya koymuştur. ${ }^{38} \mathrm{Bu}$ sebeple döner aletlerin yerine kullanılmaya başlanan piezo cerrahi cihazlar, kemiği keserken yanındaki yumuşak dokuya zarar vermemesi nedeniyle tercih edilmektedir. ${ }^{38}$ Piezo cerrahi alet kullanılarak yapılan pencere hazırlığı sonrasında meydana gelen perforasyon riski döner aletlerle karşılaştıııldığında \%17.5'e ve hatta \%3.6'ya kadar düştüğünü gösteren araştırmalar bulunmaktadır. ${ }^{39,40}$ Piezo cerrahi aletinin cerrahi sırasında travma ve kanamayı azalttığı ve alet kitinde bulunan farklı uçların aynı zamanda membran perforasyon riskini de azalttığı vurgulanmaktadır. ${ }^{38}$ Buna karşın her iki alet kullanımının bilateral sinüs ogmentasyonunda karşılaştıııdığı 
bir çalışmada, oluşan perforasyon riskinin benzer olduğu bildirilmiştir. ${ }^{41}$ Von-Arx ve ark. ${ }^{42}$ yaptıkları bir çalışmada, piezo cerrahi alet kullanımının sinüs ogmentasyon işlemi sırasında fazla tecrübesi olmayan hekimlerin sinüs membranı perforasyon riskini azalttığı, fakat deneyimli hekimlerde hem konvansiyonel alet hem de piezo cerrahi alet ile eleve edilen sinüs membranı perforasyon oranının benzer olduğu saptanmıştır.

Literatürde sinüs membran kalınlığının perforasyon oluşumuna etki eden faktörler arasında yer aldığı belirtilmektedir. ${ }^{43}$ Kalın membranlar $1.5 \mathrm{~mm}$ ve üzerinde, ince membranlar ise 1.5 mm'den az kalınlığa sahip membranlar olarak tarif edilmektedir. ${ }^{44}$ Bununla birlikte yapılan araştırmalarda hem kalın hem de ince membranların perforasyon riskinin benzer olduğu bildirilmiştir. ${ }^{45,30}$ Sinüs membranı kalınlığının perforasyon riskine etkisi hala tartışmalı olmakla birlikte yapılan son sistematik derlemede her ne kadar istatistiksel bir farklıı̆a ulaşmasa da kalın membranların perforasyon riskini arttırabileceği vurgulanmıştır. ${ }^{43}$ Bununla beraber cerrahın deneyimi, kullanılan alet ve sinüste septa varlığı gibi fak törlerin membran perforasyonunda çok daha önemli bir rol oynadığı belirtilmiştir. ${ }^{27,43}$

Membran perfore olduğunda yapılması gereken ilk hamle, membran elevasyonunun yırtılmanın olduğu bölgenin tam ters tarafından yapılarak, perforasyonun büyümesinin engellenmesidir. ${ }^{46}$ Membran tüm duvarlardan yavaşça eleve edilerek gerilimi en aza indirilmelidir. Perforasyonun yeri ve büyüklüğü değerlendirilerek tedavi seçenekleri gözden geçirilmelidir. Eğer perforasyon çok küçük ise genellikle pıhtı oluşumu ile kendiliğinden iyileşir. ${ }^{24}$ Küçük yırtılmalar (5 mm'den az) hızlı rezorbe olabilen membranlar kullanılarak çözümlenirken, büyük perforasyonlar (10 mm'den büyük) için daha uzun sürede rezorbe olan büyük membranlar kullanılmaktadır. ${ }^{46,47}$ Bununla birlikte literatürde fibrin yapıştırıcı ve siyanoakrilat adezivin uygulandığı ve büyük perfo rasyonlarda dikiş materyalinin de kullanıldığı çalışmalar da bulunmaktadır. ${ }^{48}$ Bazı araştırmacılar, sinüs membranın dikilmesinin daha büyük perforasyonlara sebep olabileceğini bildirmişlerdir. ${ }^{49}$ Literatürde küçük perforasyonlarda herhan- gi bir tamir işlemi yapılmadan operasyona devam edilebileceği öne sürülürken, geniş perforasyonlarda çoğunlukla operasyonun ertelenmesi önerilmektedir. ${ }^{24,50}$

Sinüs membranı perforasyonuna sebep olan bir diğer faktör ise, sinüste septa varlığıdır. ${ }^{43}$ Septa, maksiller sinüsü bir ya da daha fazla bölüme ayıran kortikal kemik çıkıntılarıdır. ${ }^{51}$ Literatürde yapılan çalışmalarda, maksiller sinüste septa oranının \%10-\%58 arasında değiştiği bildirilmektedir. ${ }^{52,53}$ Sinüste septa bulunması gerek lateral duvarda kemik penceresi açılmasını, gerekse sinüs membranının elevasyonunu zorlaştırarak komplikasyon riskini arttırmaktadır. ${ }^{54}$ Son yıllarda yapılan çalışmalar septanın varlığı kadar yüksekliğinin de komplikasyon riskini arttırdığını ortaya koymaktadır. ${ }^{30}$ Literatürde septa sebebiyle oluşabilecek komplikasyon riskini en aza indirmek için septa yüksekliği 3 mm'den az ise, maksiller sinus duvarına uygulanacak osteotominin alt kesisinin sinüs tabanının en az 3 mm üzerinden yapılması önerilmektedir. ${ }^{44}$ Septa yüksekliğinin 3 mm'den fazla olduğu durumda ise, sinüs duvarına yapılacak olan osteotominin septa önünde ve septa arkasında olacak şekilde vertikal kesiler ile iki ayrı pencere olarak yapılması gerektiği bildirilmiştir.44,55,56 Boyne ve James ${ }^{4}$ septanın kesilerek çıkarılmasını önermişler, böylece uygulanacak kemik greftinin bölünmeden tüm sinüs tabanına yerleştirilebileceğini bildirmişlerdir.

\section{Kanama}

Cerrahi operasyon sırasında meydana yoğun kanama sıklıkla lateral pencere tekniği sırasında meydana gelmektedir. ${ }^{57}$ Lateral pencere tekniği osteotomisi sırasında meydana gelen kanamanın kaynağı, maksillanın yan yüzü boyunca uzanan posterior superior alveoler arterin (PSAA) intraosseoz küçük dallarının travmatize edilmesidir. Flap elevasyonu ya da serbestleştirici insizyonlar sırasında PSSA'nın ek straosseoz dallarının ve infraorbital arter dallarının kesilmesi yoğun kanamaya sebep olabilmektedir. Operasyon sırasinda yoğun kanama meydana gelme riskinin oldukça az (\%2) olduğu bildirilmiştir. ${ }^{58}$ Operasyon sırasında kanama olması durumunda hastanın başının dik duruma getirilmesinin nazal mukozaya kan akışını \%38 oranında azalttığı bildirilmiştir. ${ }^{59}$ Tampon ile bası uygulaması, lokal vazokonstrüktör 
kullanımı, elektrokoter kullanımı ve sutür uygulaması diğer seçeneklerdir. ${ }^{58,59} \mathrm{Bu}$ tip bir komplikasyonun önlenmesinde KIBT ile operasyon öncesi arter lokalizasyonunun belirlenmesi önerilmektedir. ${ }^{58}$

\section{Cerrahi işlem sonrası meydana gelen}

\section{komplikasyonlar}

Operasyon sonrası enfeksiyon

Sinüs ogmentasyon cerrahisi sonrası erken dönemde meydana gelen komplikasyonların başında, operasyon sonrası enfeksiyona bağlı gelişen sinüzit oluşumu gelir. ${ }^{60,61}$ Meydana gelebilecek bir enfeksiyon, maksiller sinüsün birçok hayati yapıyla komşuluğunun bulunması sebebiyle, kavernöz sinüs trombozu gibi ciddi komplikasyonlara öncülük edebilir. Yapılan araştırmalar, varolan kronik sinüzit hikayesinin, sinüs ogmentasyonu öncesi teşhis edilememesinin akut greft enfeksiyonu riskini arttırabileceğini ortaya koymaktadır. ${ }^{62}$ Sinüs greft enfeksiyonu önemli bir komplikasyondur fakat sık karşılaşılan bir komplikasyon değildir. Literatürde meydana gelme sıklığı \% 4.7 olarak bildirilmektedir. ${ }^{63}$ Sinüs ogmentasyonu sonrası enfeksiyon riskini azaltmak için, cerrahi öncesi tanının iyi yapılarak, sinüste var olan patolojik durumun teşhis edilmesi, çekilmesi gereken umutsuz dişlerin lateral pencere operasyonundan önce çekilmesi ve periodontal tedavi tamamlanmadan cerrahiye başlanmaması önerilir. ${ }^{11}$ Asepsinin yetersiz olması, akut sinüzit tablosunun gelişmesinin birincil faktörüdür. Sinüs membranının yeniden şekillendirilmesi sırasında cerrahi alanın ya da greftin tükürük ile kontamine olması ve greftin sinüs içerisine girmesi de enfeksiyona uygun zemin oluşturmaktadır. Maksiller sinüsün enfeksiyonunda yüzde ödem, eritem, ağrı, palpasyonda hassasiyet, burundan pürülan akıntı gibi şikayetler görülmektedir. ${ }^{44}$ Tedavi protokolünde geniş-spekturumlu antibiyotik kullanımı, sinüsün endoskopik incelemesi, sinüs cerrahisi ve sinüsün yıkanması önerilmektedir. ${ }^{63,64}$ Yapılan çalışmalarda çoğunlukla antibiyotik olarak amoksisilin/amoksisilin+klavulanik asit reçete edildiği, ostiumun kapanmaması ve drenajın sağlanması için de nazal dekonjeastanlardan yararlanıldığ bildirilmektedir. ${ }^{44,57}$
Sinüsün burun boşluğu ile irtibatını sağlayan ve ostium denilen oluşum, hem sinüsün ventilasyon (hava akımı) hem de drenaj (boşalma) fonksiyonunu yerine getirir. Ostiumun kapanması, hava akımının ve drenajın bozulmasına ve alanda salgı birikiminin olmasına, bakterilerin üremesine zemin hazırlamaktadır. Sinüs ogmentasyonu sonucu meydana gelen enfeksiyon, maksiller sinüsün apikal yönde fazla doldurulması, sinüs membranının perfore edilerek greft partiküllerinin sinüse dolması gibi sebepler, ostium blokajına sebep olabilmektedir. ${ }^{11}$ Bu durumda hastalar genellikle operasyonu takip eden günlerde boğazlarında greft partikülleri olduğunu rapor ederler. Bu durum hem sinüsün iyileşme sürecini bozmakta hem de greftlenmiş sinüs içerisinde normalde ortamda bulunmayan zararlı bakterilerin üremesine ve sinüs içerinde basınç artışına sebep olmaktadır.62 Bu durum sinüzit gelişiminde de aktif rol oynamaktadır. ${ }^{65}$ Post-operatif sinüzitin tedaviye cevap vermemesi ciddiye alınmalı, tedaviye daha güçlü antibiyotik ile devam edilmeli ve kulak-burun-boğaz uzmanı ile konsültasyon yapılmalıdır.11

\section{Hematom}

Sinüs cerrahisi sırasında ya da sonrasında meydana gelen kontrol edilemeyen kanama, hematom oluşumu ve greft kaybına sebep olmaktadır. Genellikle kanamanın başlıca sebebi, PSAA ve anastomozlarının zarar görmesidir.66 $\mathrm{He}$ matom olan bölgede enfeksiyon gelişiminin önlenmesi için 10 gün süre ile amoksisilin+klavulonik asit kombinasyonu kullanımı önerilmektedir. ${ }^{11}$

\section{Yara iyileşmesi}

Flap dizaynının ve dikiş tekniğinin doğru seçilmemesi, rahatlatıcı ensizyonların yapılmaması, yara bölgesinin açılması ve ardından bölgenin enfekte olmasıyla sonuçlanır. Oluşan enfeksiyonun yayılması, fistül oluşumuna neden olarak sinüsün ağız boşluğuna açılmasına kadar gidebilir. ${ }^{11}$ Böyle bir durumda uygulanan greft materyali kısmen yada tamamen çıkarılmalı ve bölgenin primer kapatılması için saplı greftler yada dişeti grefti uygulanmalıdır. ${ }^{37}$ Oluşan enfeksiyonun kontrol altına alınamaması ve oluşan oro-antral açıklığın kapanmaması durumunda kulak-burun-boğaz uzmanı ile konsültasyon yapılmalıdır. 


\section{Vertigo}

Operasyon sonrası geçmeyen ağrı, baş dönmesi, bulantı ve benign paroksismal pozisyonel vertigo, osteotom sinüs cerrahisi sırasında çekiç darbelerinin yoğun uygulanması sonrası nadir olarak görülen komplikasyon olarak rapor edilmiştir. ${ }^{67,68}$ Cerrahinin bilinçli sedasyon altında yapılması, osteotom sırasında çekiç darbelerinin aralıklı uygulanması ve cerrahın hastalarında cerrahi işlem gerçekleşmeden önce vertigo hikayesi olup olmadığını sorgulaması önerilmektedir. ${ }^{68}$

\section{Cerrahi işlem sonrası uzun dönemde görülen komplikasyonlar}

Greft kaybı

Sinüs ogmentasyonu sırasında greft materyali sinüs içerisine doldurulurken, belirli bir sıra takip edilmelidir. Uygulamaya öncelikle anterior duvardan başlanmalı, sırasıyla posterior, medial ve lateral duvarlar doldurulmalı, vestibül duvar en sona bırakılmalıdır. ${ }^{62}$ Cerrahi işlem sırasında greft materyalinin sırayla doldurulmaması ve greft uygulanması sırasında fazla kuvvet uygulanması greft materyalinin sinüs içerisine kaçmasına neden olur. Membran perforasyonu olması durumunda kollajen membran kullanılarak perforasyonun kapatılması önerilmektedir. Bu durumda önerilen bir başka yöntem ise, greft partiküllerinin bir arada kalmasını sağlamak amacıyla greft materyaline kalsiyum sülfat eklenmesidir. ${ }^{6}$

\section{Implantın sinüse kaçması}

Sinüs ogmentasyonu sonucu nadir olarak görülen bir diğer komplikasyon ise implantın yer değiştirmesi/sinüs içine kaçmasıdır. Alveol kreti kalınlığının dikkate alınmadan yanlış planlama yapılması yada cerrahi deneyimin yetersiz olduğu durumlar primer stabilizasyonda problem meydana getirmektedir. ${ }^{69}$ Sinüs içerisine itilen implantlar herhangi bir enfeksiyona neden olmayabilecekleri gibi, oroantral açıklığa ve/veya maksiller, etmoidal ve frontal sinüslerin enfeksiyonuna da sebep olabilirler. ${ }^{69}$ Sinüse kaçan implantın çıkarıması ve ilgili bölgedeki enfeksiyonun kontrol altına alınması için iki tedavi yöntemi sıklıkla kullanılmaktadır. Bu yöntemler maksiller duvar üzerinde lateralinde kemik penceresi açılması ve burundan geçerek yapılan endoskopik sinüs cerrahisidir. ${ }^{70,71}$ Her iki yöntem de efektif olmakla beraber endoskopik cerrahide var olan bir oro-antral açıklığı kapatmak mümkün olmamaktadır. Diğer yandan endoskopik cerrahi postoperatif hasta konforu açısından avantajlıdır. ${ }^{59,69}$

\section{SONUÇ}

Maksiller sinüs ogmentasyonu, dişsiz maksiller sahanın rehabilitasyonunda kabul görmüş, başarılı ve güvenilir bir tekniktir. Maksiller sinüse komşuluğu bulunan hayati organlar sebebiyle, cerrahi girişim ve sonrasında oluşabilecek komplikasyonlar hasta açısından çok ciddi sonuçlar doğurabilmektedir. Komplikasyon riskini ve yaygınlığını azaltmak için her vakanın detaylı ele alınması, bireye ait sistemik hastalıklar, sigara kullanımı, parafonksiyonel alışkanlıklar ve implant yapılacak bölgeye ait sert ve yumuşak dokuların ayrıntılı olarak incelenmesi komplikasyon riskini azaltmakta ve tedavinin uzun dönem başarısında anahtar rol oynamaktadır.

\section{KAYNAKLAR}

1. Janner SF, Caversaccio MD, Dubach P, Sendi P, Buser D, Bornstein MM. Characteristics and dimensions of the Schneiderian membrane: a radiographic analysis using cone beam computed tomography in patients referred for dental implant surgery in the posterior maxilla. Clin Oral Implants Res 2011;22: 1446-1453.

2. Del Fabbro M, Testori T, Francetti L, Weinstein R. Systematic review of survival rates for implants placed in the grafted maxillary sinus. Int J Periodontics Restorative Dent 2004; 24: 565-577.

3. Boyne PJ. Lectures to postgraduate course, US Navy Dental School, National Naval Medical Center, Bethesda, MD, 1965-1968.

4. Boyne PJ, James RA. Grafting of the maxillary sinüs floor with autogenous marrow and bone. J Oral Surg 1980; 38 : 613-616.

5. Summers RB. A New consept in maxillary implant surgery: The osteotom technique. Compend Contin Educ 
Dent 1994; 15: 152-160.

6. Fugazotto PA. Augmentation of the posterior maxilla: a proposed hierarchy of treatment selection. J Periodontol 2003; 4: 1682-1691.

7. Pjetursson BE, Tan WC, Zwahlen M, Lang NP. A systematic review of the success of sinus floor elevation and survival of implants inserted in combination with sinus floor elevation. J Clin Periodontol 2008; 35: 216-240.

8. Del Fabbro M,Rosano G, Taschieri S. Implant survival rates after maxillary sinüs augmentation. Eur J Oral Sci 2008; 116: 497-506.

9. Tan WC, Lang NP, Zwahlen M, Pjetursson BE. A systematic review of the success of sinus floor elevation and survival of implants inserted in combination with sinus floor elevation. Part II: transalveolar technique. J Clin Periodontol 2008; 35: 241-54.

10. Lai HC, Zhuang LF, Lv XF, Zhang ZY, Zhang YX, Zhang ZY. Osteotome sinus floor elevation with or without grafting: a preliminary clinical trial. Clin Oral Implants Res 2010; 21: 520-526.

11. Fugazzotto P, Melnick PR, Al-Sabbagh M. Complications when augmenting the posterior maxilla. Dent Clin North Am 2015; 59: 97-130.

12. Vogiatzi T, Kloukos D, Scarfe WC, Bornstein MM. Incidence of anatomical variations and disease of the maxillary sinuses as identified by cone beam computed tomography: a systematic review. Int J Oral Maxillofac Implants 2014; 29 : 1301-1314.

13. Chiapasco M, Rosenlicht JL, Ruggiero SL, Schneider RE. Contraindications for Sinus Graft Procedures. In: Jensen OT. Sinus Bone Graft. 2nd ed.,Quintessence ; 2006: 87-101.

14. Tawil G, Younan R, Azar P, Sleilati G. Conventional and advanced implant treatment in the type II diabetic patient: surgical protocol and long-term clinical results. Int $\mathrm{J}$ Oral Maxillofac Implants 2008; 23: 44-52.

15. Timmenga NM, Raghoebar GM, van Weissenbruch $R$, Vissink A. Maxillary sinusitis after augmentation of the maxillary sinus floor: a report of 2 cases. J Oral Maxillofac Surg 2001; 59: 200-204.
16. Alkan A1, Celebi N, Baş B. Acute maxillary sinusitis associated with internal sinus lifting: report of a case. Eur J Dent. 2008; 2: 69-72.

17. Harris D, Horner K, Gröndahl K, Jacobs R, Helmrot E, ve ark. E.A.O. guidelines for the use of diagnostic imaging in implant dentistry 2011. A consensus workshop organized by the European Association for Osseointegration at the Medical University of Warsaw. Clin Oral Implants Res 2012; 23 : 1243-1453.

18. Mozzo P, Procacci C, Tacconi A, Martini PT, Andreis IA. A new volumetric CT machine for dental imaging based on the cone-beam technique: preliminary results. Eur Radiol 1998; 8: 1558-1564.

19. Lana JP, Carneiro PM, Machado Vde C, de Souza PE, Manzi FR,ve ark. Anatomic variations and lesions of the maxillary sinus detected in cone beam computed tomography for dental implants. Clin Oral Implants Res 2012; 23: 13981403.

20. Gurler G, Delilbasi C. Relationship between preoperative cone beam computed tomography and intraoperative findings in sinus augmentation. Int $\mathrm{J}$ Oral Maxillofac Implants 2015; 30: 1244-1248

21. American Academy of Periodontology: Position paper: Tabocco use and the periodontal patient.J Periodontol 1999; 70: 1419-1421.

22. Moraschini V, Barboza Ed. Success of dental implants in smokers and non-smokers: a systematic review and meta-analysis. Int J Oral Maxillofac Surg 2016; 45: 205-15.

23. van den Bergh JP, ten Bruggenkate CM, Krekeler G, Tuinzing DB. Maxillary sinusfloor elevation and grafting with human demineralized freeze dried bone. Clin Oral Implants Res 2000; 11: 487-493.

24. van den Bergh JP, ten Bruggenkate CM, Disch FJ, Tuinzing DB. Anatomical aspects of sinus floor elevations. Clin Oral Implants Res 2000; 11:256-265.

25. Szabo G\& Toth C. Komplikationshâufigkeiten beim Sinus-lift. Z Zahnârztl Implantol 17: 132-134.

26. Schwartz-Arad D, Herzberg R, Dolev E. The prevalence of surgical complications of the sinus graft procedure and 
their impact on implant survival. J Periodontol 2004; 75: 511 . 516.

27. Wallace SS, Mazor Z, Froum SJ, Cho SC, Tarnow DP. Schneiderian membrane perforation rate during sinus elevation using piezosurgery: clinical results of 100 consecutive cases. Int J Periodontics Restorative Dent 2007; 27: 413-419.

28. Khoury F.Augmentation of the sinus floor with mandibular bone block and simultaneous implantation: a 6-year clinical investigation. Int J Oral Maxillofac Implants 1999; 14: 557-564.

29. Watzek G, Uhn CW, Haas R. Anatomic and physiologic Fundamentals of sinus floor augmentation. In:Jensen OT. The Sınus Bone Graft. London: Quintessence Publishing Co, 1999, 31-48.

30. Von Arx T, Fodich I, Borstein MM, Jensen SS. Perforation of the sinus membrane during sinus floor elevation: a retrospective study of frequency and possible risk factors. Int $\mathrm{J}$ Oral Maxillofac Imp 2014; 29: 718-726.

31. Vlassis JM, Fugazzotto PA. A classification system for sinus membrane perforations during augmentation procedures with options for repair. J Periodontol 1999; 70: 692699.

32. Cho SC, Wallace SS, Froum SJ, Tarnow DP.Influence of anatomy on Schneiderian membrane perforations during sinus elevation surgery: three-dimensional analysis. Pract Proced Aesthet Dent 2001; 13: 160-163.

33. Ardekian L1, Oved-Peleg E, Mactei EE, Peled M. The clinical significance of sinus membrane perforation during augmentation of the maxillary sinus. J Oral Maxillofac Surg 2006; 64: 277-282.

34. Barone A, Santini S, Sbordone L, Crespi R, Covani U. A clinical study of the outcomes and complications associated with maxillary sinus augmentation. Int $\mathrm{J}$ Oral Maxillofac Implants 2006; 21:81-85.

35. Proussaefs P, Lozada J, Kim J, Rohrer MD. Repair of the perforated sinus membrane with a resorbable collagen membrane: a human study. Int J Oral Maxillofac Implants 2004; 19: 413-420.
36. Nolan PJ, Freeman K, Kraut RA. Correlation between Schneiderian membrane perforation and sinus lift graft outcome: a retrospective evaluation of 359 augmented sinus. J Oral Maxillofac Surg 2014; 72: 47-52.

37. Hernández-Alfaro F, Torradeflot MM, Marti C. Prevalence and management of Schneiderian membrane perforations during sinus-lift procedures. Clin Oral Implants Res 2008; 19: 91-98.

38. Wallace SS, Mazor Z, Froum SJ, Cho SC, Tarnow DP. Schneiderian membrane perforation rate during sinus elevation using piezosurgery: clinical results of 100 consecutive cases. Int J Periodontics Restorative Dent 2007; 27: 413-419.

39. Weitz DS, Geminiani A, Papadimitriou DE, Ercoli C, Caton JG. The incidence of membrane perforation during sinus floor elevation using sonic instruments: a series of 40 cases. Int J Periodontics Restorative Dent 2014; 34: 105-112. 40. Tascono NJ, Holtzclaw D, Rosen PS. The effect of piezoelectric use on open sinus lift perforation: a retrospective evaluation of 56 consecutively treated cases from private practices. J Periodontol 2010; 81: 167-171.

41. Barone A, Santini S, Marconcini S, Giacomelli L, Gherlone $\mathrm{E}$, Covani U. Osteotomy and membrane elevation during the maxillary sinus augmentation procedure. A comparative study: piezoelectric device vs. conventional rotative instruments. Clin Oral Implants Res 2008; 19: 511-515.

42. Von Arx T, Fodich I, Bornstein MM, Jensen SS. Perforation of the sinus membrane during sinus floor elevation: a retrospective study of frequency and possible risk factors. Int J Oral Maxillofac Implants 2014; 29: 718-726.

43. Monje A, Diaz KT, Aranda L, Insua A, Garcia-Nogales a et al. Schneiderian membrane thickness and clinical ımplications for sinus augmentation: A systematic review and meta-regression analyses. J Periodontol 2016; 87: 888-899.

44. Çakarer S, Erdem MA, Çankaya B, Keskin. C. Sinus tabanı yükseltilmesinde komplikasyonlar ve tedavi seçenekleri. İstanbul Üniversitesi Dişhekimliği Fakültesi Dergisi 2009; 43: 133-139.

45. Cortes AR, Cortes DN, Arita ES. Effectiveness of piezo- 
electric surgery in preparing the lateral window for maxillary sinus augmentation in patients with sinüs anatomical variations: A case series. Int J Oral Maxillofac Implants 2012; 27: 1211-1215.

46. Testori T, Wallace SS, Del Fabbro M, et al. Repair of large sinusmembrane perforations using stabilized collagen barrier membranes: sur-gical techniques with histologic and radiographic evidence of success. Int. J Periodontics Restorative Dent 2008; 28: 9-17.

47. Vlassis JM, Fugazzotto PA. A classification system for sinus membrane perforations during augmentation procedures with options for repair. J Periodontol 1999; 70: 692699.

48. Becker ST, Terheyden H, Steinriede A, Behrens E, Springer I, et al. Prospective observation of 41 perforations of the Schneiderian membrane during sinus floor elevation. Clin Oral Implants Res 2008; 19: 1285-1289.

49. Pikos MA. Maxillary sinus membrane repair: update on technique for large and complete perforations. Implant Dent 2008; 17: 24-31.

50. Ziccardi VB, Bets NJ. Complications of maxillary sinus augmentation. In: Jensen OT. Editor. The Sinus bone graft, London, Quintessence Publishing Co, 2006, p 103-114.

51. Pommer B, Ulm C, Lorenzoni M, Palmer R, Watzek G, et al. Prevalence, location and morphology of maxillary sinus septa: systematic review and meta-analysis. J Clin Periodontol $2012 ; 39$ : 769-773.

52. Yang HM, Bae HE, Won SY, Hu KS, Song WC, et al. The buccofacial wall of maxillary sinus: an anatomical consideration for sinus augmentation. Clin Implant Dent Relat Res $2009 ; 11: 2-6$.

53. Maestre-Ferrin L, Carillo-Garcia C, Galangil S, Penarrocha-Diago M. Prevalence, location, and size of maxillary sinüs septe: panoramic radiograph versus computed tomography scan. J Oral Maxillofac Surg 2011; 69; 507-511.

54. Betss NJ, Miloro M. Modification of the sinus lift procedure for septa in the maxillary antrum. J Oral Maxillofac Surg 1994; 52: 332-333.

55. Özeç I, Kiliç E, Muderris S. Maksiller sinüs septa: Bilgisa- yarlı tomografi ve panoramik radyografi ile değerlendirme. CÜ Diş Hek Fak Derg 2008; 11: 82-86.

56. Garg AK. Bone biology, harvesting, grafting for dental implants rationale and clinical applications. 1th edition. Illionis: Quintessence Publishing Co, Inc. 2004. p. 171-211.

57. Moreno Vazquez JC, Gonzalez de Rivera AS, Gil HS, Mifsut RS. Complication rate in 200 consecutive sinus lift procedures: guidelines for prevention and treatment. J Oral Maxillofac Surg 2014; 72: 892-901.

58. Zijderverd SA, van der Bergh JP, Schulten EA, et al. Anatomical and surgical findings and complications in 100 consecutive maxillary sinüs floor elvation procedures. J Oral Maxillofac Surg 2008; 66: 1426-1438.

59. Katranji A, Fotek P, Wang HL. Sinus augmentation complications: etiology and treatment. Implant Dent 2008; 17 : 339-349

60. Timmenga NM, Raghoebar GM, Boering G, van Weissenbruch R. Maxillary sinus function after sinus lifts for the insertion of dental implants. J Oral Maxillofac Surg 1997; 55: 936-939

61. Tidwell JK, Blijdorp PA, Stoelinga PJ, Brouns JB, Hinderks F. Composite grafting of the maxillary sinus for placement of endosteal implants. A preliminary report of 48 patients. Int J Oral Maxillofac Surg 1992; 21: 204-209.

62. Testori T,editör. Maxillary sinus surgery and alternatives in treatment. Hanover Park (IL): Quintessence International; 2009.p. 191-217.

63. Jensen SS, Terheyden H. Bone augmentation procedures in localized defects in the alveolar ridge: clinical results with different bone grafts and bone-substitute materials. Int J Oral Maxillofac Implants 2009; 24: 218-236.

64. Kahnberg KE, Vannas-Löfqvist L. Sinus lift procedure using a 2-stage surgical technique: I. Clinical and radiographic report up to 5 years. Int J Oral Maxillofac Implants 2008; 23: 876- 884

65. Timmenga NM, Raghoebar GM, Liem RSB, van Weissenbruch R, Manson WL, Vissink A. Effects of maxillary sinus floor elevation surgery on maxillary sinus physiology. Eur J Oral Sci 2003; 111: 189-197. 
66. Solar P, Geyerhofer U, Traxler H, Windisch A, Ulm C, Watzek G. Blood supply to the maxillary sinus relevant to sinus floor elevation procedures. Clin Oral Implants Res 1999;

10: 34-44.

67. Greenstein G, Cavallaro J. Transcrestal sinus floor elevation with osteotomes simplified technique and management of various scenario. Compend Contin Educ Dent 2011; 32: 14-20.

68. Akcay H, Ulu M, Kelebek S, Aladag I. Benign Paroxysmal Positional Vertigo Following Sinus Floor Elevation in Patient with Antecedents of Vertigo. J Maxillofac Oral Surg 2016; 15: 351-354.

69. Chiapasco M, Felisati G, Maccari A, Borloni R, Gatti F, Di Leo F. The management of complications following displacement of oral implants in the paranasal sinuses: a multicenter clinical report and proposed treatment protocols. Int J Oral Maxillofac Surg 2009; 38: 1273-1278.

70. Raghoebar GM, Vissink A. Treatment for an endosseous implant migrated into the maxillary sinus not causing maxillary sinusitis: case report. Int J Oral Maxillofac Implants 2003; 18: 745-749.

71. Kitamura A. Removal of a migrated dental implant from a maxillary sinus by transnasal endoscopy. $\mathrm{Br} \mathrm{J}$ Oral Maxillofac Surg 2007; 45: 410-411 